\title{
DOS VISIONES DEL QUIJOTE (UNAMUNO VERSUS CERVANTES)
}

\author{
Manuel Romero Luque \\ Universidad de Sevilla
}

De todos es sabido que El Quijote no sólo ha dado pie a infinidad de estudios filológicos, críticos o lingüísticos, e incluso a otros de las más diversas disciplinas (botánica, medicina o gastronomía), sino que ha servido también de base para la creación literaria. Así, escritores españoles y extranjeros de diversas épocas, y hasta nuestros días, han tenido en la genial obra cervantina una constante fuente de inspiración para el desarrollo de sus propios trabajos. Pero es, sin duda, en los primeros años del siglo XX cuando un grupo importante de escritores van a volver los ojos a la figura literaria de Alonso Quijano y su entorno: Rubén Darío, Azorín, Maeztu, Unamuno y Ortega y Gasset serán los principales en el ámbito hispánico'.

Dos serán las razones fundamentales que potencien este hecho: el Desastre del 98 y el reconocimiento progresivo del valor simbólico que el hidalgo protagonista había venido alcanzando desde el romanticismo. Ambos factores van a unirse, aunque de diverso modo, en cada uno de los escritores nombrados. Por un lado, conviene recordar que el año 1898 no significa sólo la pérdida de las últimas colonias, el punto final de la larga sangría de vidas, esfuerzos y dineros que supuso la guerra de Cuba o el reconocimiento, con el Tratado de París, de la pérdida de toda influencia española; sino también, y esto será lo más grave, el absoluto desánimo que invade a los españoles y los paraliza. A unos, porque temían el desenlace y lamentaron no haber sido escuchados en sus protestas previas; a otros, porque despiertan de un letargo inducido por la tradición, y por muchos de los políticos del momento, para pasar a vivir en la más amarga pesadilla.

Ante este panorama político y social, entra en liza el segundo de los factores: el valor simbólico del hidalgo manchego. Éste, progresivamente, había dejado de ser visto como un personaje disparatado, aunque lleno de buenas intenciones, que sólo provocaba la risa del lector, para convertirse en un arquetipo del héroe que lucha por su ideal y contra el que nada pueden las circunstancias por adversas que sean. Si España y los españoles necesitaban una catarsis que los sacara de su estado de postración extrema, la figura cervantina será la elegida para abanderar el proyecto que instigan con su pluma los escritores más arriba mencionados, entre otros. El modelo cuadra a la perfección con la visión de la historia que se ofrece ante los ojos de aquellos ciudadanos de principios del XX. Se pretende reforzar la idea de la capacidad impulsora de un país que, reconociendo su

\footnotetext{
${ }^{1}$ Recuérdense, entre otros, la "Letanía a Nuestro Señor Don Quijote" o el "Soneto a Cervantes" de Rubén Darío, incluidos en sus Cantos de vida y esperanza (1905); La ruta de Don Quijote (1905) escrita por Azorín o sus innumerables artículos recopilados en dos tomos: Con Cervantes (1947) y Con permiso de los cervantistas (1948); de Ramiro de Maeztu, y precediendo a su Don Quijote, Don Juan y la Celestina (1926), no deben olvidarse sus artículos "El libro de los viejos"(1901), publicado en La Correspondencia de España, y "Ante las fiestas del Quijote" (1903) en Alma española; y, por último, dejando al margen por ahora la figura de Unamuno, las Meditaciones del Quijote (1914) de José Ortega y Gasset.
} 
historia, se atreva a labrarse un futuro al margen de las glorias pasadas. En consecuencia, se le quiere hacer saber que no debe importar la caída, si se tienen fuerzas para levantarse y que, como El Caballero de la Triste Figura, tras los pasos desventurados hay que erguirse cuantas veces haga falta. Sólo deja huella la derrota cuando falta la fe.

Tal vez, por este motivo, se prefirió al viejo y escuálido manchego frente a otros personajes de nuestra historia y nuestra literatura que también salieron entonces a la palestra, como, por ejemplo, El Cid; pues éste recibe un solo golpe, aunque todo lo duro que se quiera, en su dilatado discurrir aventurero ${ }^{2}$. De este modo, si el antes y el después del destierro para el soldado de Vivar son la gloria y el triunfo, en la vida del hidalgo de mediano pasar que nos pinta Cervantes hay muchas batallas y casi ninguna victoria que ofrecer y, sin embargo, mantiene, pese a esa implacable adversidad que le persigue, una constancia de ideales que apenas conoce el desaliento. Por ello, cuando se sitúan frente a él los demás personajes de la novela, sólo pueden mostrar, aun antes que la risa, su asombro por la perplejidad que les causa esa débil figura que no rehúsa ninguna ocasión para el combate.

Este es, brevemente esbozado, el planteamiento general de la época para autores y lectores cuando, en 1905, sale a la luz la obra de don Miguel de Unamuno Vida de Don Quijote y Sancho. No obstante, una cuestión preliminar, referida a dicho año de publicación, debe ser tenida en cuenta, pues, de otro modo, podría pensarse que la obra de Unamuno estuvo motivada por la intención de conmemorar el tercer centenario del texto original de Cervantes, y nada más lejos de alguien tan enemigo de fastos y celebraciones oficiales. Él mismo acusó recibo de esta circunstancia, tal vez por haber llegado a sus oídos alguna imputación directa o velada de oportunismo literario, negando de forma inconcusa en las primeras palabras del prólogo a su segunda edición que ésta pudiera ser considerada una "obra de centenario". Más revelador puede ser, en este sentido, la simple revisión del índice de sus Obras completas donde se comprueba esa profunda preocupación que la obra de Cervantes y su principal protagonista alcanzan dentro de su extensa producción bibliográfica. En un periodo cronológico que abarca desde 1895 hasta 1932 pueden encontrarse más de una veintena de ensayos breves dedicados a estos motivos; ; de tal manera que es esta continua insistencia por examinar los más íntimos recovecos de la obra cervantina, durante casi cuarenta años, el testimonio más incuestionable de la larga preocupación del rector salmantino, hasta el punto de convertirse en una obsesión personal que antecede y sobrepasa con creces la data conmemorativas.

${ }^{2}$ Cfr. Alberto Navarro, "El Cid y Don Quijote" en El Quijote español del siglo XVII, Madrid, Rialp, 1964, pp. 322-405.

${ }^{3}$ Cfr. Miguel de Unamuno, Vida de Don Quijote y Sancho, Madrid, Alianza, 1987, p. 19. En adelante, las citas se harán siempre por esta edición, indicándose entre paréntesis la página correspondiente a la misma. Las referencias en nota, sin reproducción textual, aparecerán con las siglas $V D Q S$, seguidas del número de página.

${ }^{4}$ De ese amplio conjunto, citaremos algunos fundamentales: “iMuera Don Quijote!” (1898), "El sepulcro de Don Quijote" (1906), "Don Quijote y Bolívar" (1907), "La traza cervantesca" (1917), "En un lugar de La Mancha..." (1932). Cfr. Miguel de Unamuno, Obras completas, introducción, bibliografía y notas de Manuel García Blanco, Madrid, Escelicer, 1966-1970, 8 vols. (Véase, especialmente, el tomo VII:Meditaciones y ensayos espirituales, pp. 1191- 1256).

${ }^{5}$ Existen indicios del interés de don Miguel por escribir una obra como la publicada en 1905 desde el año 1899 , si bien la redacción definitiva tiene lugar en dos fases: el verano de 1904, en el que desarrolla el plan general de la obra, y las vacaciones navideñas de dicho año, en las que amplía lo anterior, añadiendo numerosas citas y 
Por otra parte, su autor se manifestó en múltiples ocasiones afirmando que la novela original no había sido entendida satisfactoriamente ni por la crítica, ni por el propio Cervantes; afirmación ésta que es, sin duda, sorprendente para quienes se enfrentan por primera vez con el ensayo unamuniano. Así, de un lado, su postura contra el cervantismo se inserta dentro de una línea más amplia, que aflora en muchos de sus escritos, contra una erudición estéril que convierte la obra literaria en monumento arqueológico, preocupada por la filiación historicista de aspectos nimios que distraen al amante de la literatura de la comprensión de la obra que es objeto de estudio y hace de la palabra viva letra muerta. De otro, el rector salmantino se opone tanto a aquéllos que deifican a Cervantes, como a los que se contentan con afirmar que el escritor alcalaíno no pasó de ser un ingenio lego, cuya obra apenas fue el fruto afortunado de un autor mediocre que acertó a plasmar unos personajes sin igual ${ }^{6}$. Unamuno, siguiendo esta última senda, da un paso más y coloca a Cervantes por debajo de sus criaturas, le achaca endeblez de ingenio, le atribuye el papel de mero copista del relato ${ }^{7}$, incapaz de comprender a sus protagonistas 8 , en el extremo, en una de sus logradas paradojas, hace de él un personaje de ficción?. En definitiva, a don Miguel de Unamuno no le preocupan ni Cervantes ni los cervantistas, a ninguno de ellos dedica su atención ${ }^{10}$. Su interés se centra sólo en los dos personajes principales; de este modo, su obra es, exclusivamente, un conjunto de comentarios personales sugeridos por una lectura atenta de la novela original.

extendiéndose en el comentario de determinados pasajes, sobre todo con referencias a la realidad contemporánea. Para la génesis de la obra unamuniana y su publicación, véase Manuel García Blanco, "Introducción” al tomo III: Nuevos ensayos en Obras completas, cit., pp. 7-15. Sobre el autógrafo, conservado en la Casa Museo de Unamuno en Salamanca, véase Alberto Navarro, "Introducción” a Miguel de Unamuno, Vida de Don Quijote y Sancho, Madrid, Cátedra, 1988, pp. 120-123.

${ }^{6}$ Véase Alberto Navarro, "Introducción”, cit., pp. 17-68.

${ }^{7}$ VDQS, p. 284.

${ }^{8}$ Al comentar la aventura de los galeotes, apostilla Unamuno: "Mi fe en Don Quijote me enseña que tal fue su íntimo sentimiento, y si no nos lo revela Cervantes, es porque no estaba capacitado para penetrar en él. No por haber sido su evangelista hemos de suponer fuera quien más adentró en su espíritu. Baste que nos haya conservado el relato de su vida y hazañas" (p. 96).

${ }^{9}$ VDQS, p. 284-285.

${ }^{10}$ Don Miguel insistirá en esta idea en múltiples ocasiones. Así, en la conclusión a Del sentimiento trágico de la vida, titulada "Don Quijote en la tragicomedia europea contemporánea", escribe refiriéndose a la obra que estudiamos: "Escribí aquel libro para repensar el Quijote contra cervantistas y eruditos, para hacer obra de vida de lo que era y sigue siendo para los más letra muerta. ¿Qué me importa lo que Cervantes quiso o no quiso poner allí y lo que realmente puso? Lo vivo es lo que allí yo descubro, pusiéralo o no Cervantes, lo que yo allí pongo y sobrepongo y sotopongo, y lo que ponemos allí todos" (Miguel de Unamuno, Del sentimiento trágico de la vida, introducción de Pedro Cerezo-Galán, Barcelona, Óptima, 1997, p. 304). 
Ahí radica la peculiaridad y el éxito del ensayo unamuniano. Bien pronto, los lectores supieron reconocer que no se trataba de una obra crítica sino de una texto literario que, partiendo, a su vez, de otra obra literaria, elevaba su vuelo con ritmo propio. La fuerte intertextualidad que se establece entre la Vida de Don Quijote y Sancho y El ingenioso hidalgo Don Quijote de La Mancha permite al lector ir trazando puentes entre ambas orillas, desde los cuales puede observar paisajes diferentes de un mismo lugar, aquél por el que discurre el río de la vida del enjuto caballero y su confidente. Al igual que Cervantes hiciera trescientos años antes, don Miguel nos va mostrando, ya en el siglo XX, nuevas facetas de estos dos personajes según su particular visión, según su teoría vivencial y literaria. Ese aliento vivificador que insufla de nuevo a los protagonistas los hace aparecer como criaturas coetáneas del lector. No son, pues, espectros arrancados de sus tumbas, contra los que ya Cervantes intentó precaverse al final de su Segunda Parte-, son seres al natural que permiten la observación detallada de sus acciones y la introspección minuciosa a la que Unamuno los somete. El escritor bilbaíno es, por tanto, señor de su obra, como Cervantes lo fue de su novela. Estos aspectos quedaron recogidos en las palabras liminares a la segunda edición (1913):

"Esta obra es de las mías la que hasta hoy" ha alcanzado más favor del público que me lee [...]. Y me complazco en creer que a esta mayor fortuna de esta entre mis otras obras habrá contribuido el que es una libre y personal exégesis del Quijote, en que el autor no pretende descubrir el sentido que Cervantes le diere, sino el que le da él, ni es tampoco un erudito estudio histórico. No creo deber repetir que me siento más quijotista que cervantista y que pretendo libertar al Quijote del mismo Cervantes, permitiéndome alguna vez hasta discrepar de la manera como Cervantes entendió y trató a sus dos héroes, sobre todo a Sancho. Sancho se le imponía a Cervantes, a pesar suyo. Es que creo que los personajes de ficción tienen dentro de la mente del autor que los finge una vida propia, con cierta autonomía, y obedecen a una íntima lógica de que no es del todo consciente ni dicho autor mismo" (p. 20).

Obsérvese cómo Unamuno hace hincapié en la figura del escudero que, en su obra, no es un elemento complementario del hidalgo, sino su primer discípulo y, finalmente, el continuador de su espíritu. De modo que ambos protagonistas van a ser modelados por su autor con una misma idea básica, la de que la voluntad representa la manifestación suprema de la realidad y, bajo su dominio, se sitúan todos los demás aspectos de la personalidad del individuo: conocimiento, sentimientos y dirección en la vida. Unamuno, apoyándose en Schopenhauer, hará de este voluntarismo una de sus preocupaciones esenciales y lo llevará a su máximo desarrollo en Del sentimiento trágico de la vida ${ }^{12}$. Don Miguel, sin embargo, preferirá aplicar a esta teoría la denominación de quijotismo por ser el héroe cervantino quien mejor la encarna. Pero esta calificación, al contrario de cuando la emplean la mayor parte de los críticos, no es en don Miguel un marbete que se refiera a un simple estado de locura más o menos transitoria y contagiosa (recuérdese aquí, más allá del tan citado caso

\footnotetext{
${ }^{11}$ El prólogo está fechado en enero de 1913 y, por entonces, don Miguel — a sus cuarenta y ocho años de edadcontaba ya con una dilatada bibliografía en la que, aparte sus numerosos artículos en prensa, destacan los siguientes trabajos: Paz en la guerra (1897), Amor y pedagogía (1902), En torno al casticismo (1902), Mi religión (1907), Poesías (1907), La esfinge (1909), Recuerdos de niñez y mocedad (1910), Rosario de sonetos líricos (1911), Contra esto y aquello (1912), Del sentimiento trágico de la vida (1911-1912, por entregas).

12 Esta obra, cuyo título completo reza Del sentimiento trágico de la vida en los hombres y en los pueblos, fue publicada en formato de libro en 1913, aunque apareció primero en doce entregas en la revista La España moderna, desde diciembre de 1911 hasta el mismo mes del siguiente año (así se ha hecho constar en la nota anterior). Cfr. Pedro Cerezo-Galán “Introducción” a Miguel de Unamuno,Del sentimiento ..., cit., p. 9.
} 
de Sancho, el de todos los personajes que en la venta llegan a las manos por la disputa sobre el baciyelmo o el de la dueña Doña Rodríguez cuando pide al caballero que solucione el entuerto que afecta a su hija).

Por otra parte, Unamuno sabe entroncar esta defensa a ultranza de la voluntad con otra de sus más claras influencias la del existencialismo propugnado por Kierkegaard. Este controvertido filósofo y teólogo danés criticó el énfasis de Hegel en la razón y defendió el poder de los sentimientos en el individuo, a la vez que una aproximación subjetiva a los problemas de la vida. El individuo es capaz, según la teoría de Kierkegaard, de crear su propia naturaleza mediante la capacidad de elección de la que está dotado, una elección individual y no sometida, por tanto, a normas objetivas ni universales. El rector de Salamanca defiende a su lado que los problemas fundamentales de la existencia humana desafían una explicación puramente racional y objetiva; de manera que la mayor verdad es siempre de carácter subjetivo.

"No es la inteligencia, sino la voluntad, la que nos hace el mundo, — dirá Unamuno- y al viejo aforismo escolático de nihil volitum quin praecognitum, nada se quiere antes de conocido, hay que corregirlo con un nihil cognitum, quin praevolitum, nada se conoce sin haberlo antes querido. [...] Todo es verdad, en cuanto alimenta generosos anhelos y pare obras fecundas; todo es mentira mientras ahogue los impulsos nobles y aborte monstruos estériles. Por sus frutos conoceréis a los hombres y a las cosas. Toda creencia que lleve a obras de vida es creencia de verdad, y lo es de mentira la que lleva a obras de muerte. La vida es el criterio de verdad, y no la concordia lógica, que lo es sólo de la razón. Si mi fe me lleva a crear o a aumentar mi vida, ¿para qué queréis más prueba de mi fe? Cuando la matemáticas matan, son mentira las matemáticas" (pp. 115-116).

Ese individuo preconizado que es capaz de eximirse de cualquier tipo de convencionalismo tiene que adoptar una posición fideísta extrema que lo instala en un sentimiento de angustia permanente por el temor a la nada. Así se comprende mejor el Quijote que nos presenta a lo largo de su ensayo don Miguel: un personaje que decide su posición en el mundo y que, frente a barberos, bachilleres, clérigos y familia, se atreve a pronunciar su rotundo "yo sé quién soy" en el capítulo V de la Primera Parte. Esta frase es, sin lugar a dudas, la piedra angular sobre la que se fundamenta la actitud del héroe en la obra cervantina ${ }^{13}$; y Unamuno, siempre atento a su labor profética de revelar a sus semejantes la comprensión del protagonista, le dedica una especial atención en su comentario:

"Puede el héroe decir: "yo sé quién soy", y en esto estriba su fuerza y su desgracia a la vez. Su fuerza, porque como sabe quién es, no tiene por qué temer a nadie, sino a Dios, que le hizo ser quien es; y su desgracia, porque sólo él sabe, aquí en la tierra, quién es él, y como los demás no lo saben, cuanto él haga o diga se les aparecerá como hecho o dicho por quien no se conoce, por un loco" (p. 48).

Pero no basta con decir esa frase y dejarla sonando en el aire como si de una pose más o menos afectada se tratara. Pronunciarla es una profesión de fe, de fe en Dios y de fe en el hombre; en el hombre que quiere de veras serlo. La verdadera naturaleza humana es, para Unamuno, fruto de la voluntad. No se nace hombre, más allá del aspecto aparencial, se hace uno hombre y este hacerse es siempre ir en pos de un desiderátum que lo liga a la idea de

\footnotetext{
${ }^{13}$ Cfr. Manuel Romero Luque, "Libertad y locura en El Quijote”, en Esteban Torre (ed.): Medicina y Literatura
} $V$, Sevilla, Padilla Libros, 2006. 
Dios. Las palabras de don Miguel son meridianas en este sentido, y las dirige directamente al lector, a ese lector que, cuando oye la tremenda declaración quijotesca, manifestación pura y desnuda del ser del personaje, se atreve a reírse de él y a calificarlo de arrogante, presuntuoso o loco:

"Te equivocas tú, el que dice eso; Don Quijote discurría con la voluntad, y al decir "iyo sé quién soy!”, no dijo sino “iyo sé quién quiero ser!”. Y es el quicio de la vida humana toda: saber el hombre lo que quiere ser. Te debe importar poco lo que eres; lo cardinal para ti es lo que quieras ser. El ser que eres no es más que un ser caduco y perecedero, que come de la tierra y al que la tierra se lo comerá un día; el que quieres ser es tu idea de Dios, Conciencia del Universo: es la divina idea de que eres manifestación en el tiempo y el espacio" (p. 49).

La risa que provocan en el espectador las aventuras del héroe es, para Unamuno, no sólo testimonio de la incomprensión que Don Quijote despierta en cuantos conocen sus hechos, sino manifestación palmaria de la ignorancia de éstos con respecto a su auténtico destino. El personaje cervantino se convierte en el alter ego del rector de Salamanca, sus ideales se igualan a los del hidalgo, la defensa de aquél en reivindicación de sus propios postulados filosóficos y vitales. Frente a las acusaciones que él mismo recibió de la sociedad de su época: ególatra, heterodoxo, rebelde..., el actuar del caballero le sirve de escudo y, de ahí, la reivindicación de sus palabras y de sus actuaciones a los largo de toda la obra. Podría decirse que, con la defensa de Don Quijote, Unamuno se protege a sí mismo de aquellos conciudadanos que, afectando no entenderle, lo acusan constantemente de paradójico. En definitiva, esa posición radical de autoafirmación del yo es algo que sólo pertenece a quien con ahínco lucha por su ser frente a toda adversidad:

"Sólo el héroe puede decir "¡yo sé quién soy!”, porque para él ser es querer ser; el héroe sabe quién es, quién quiere ser, y sólo él y Dios lo saben, y los demás hombres apenas saben ni quién son ellos mismos, porque no quieren de veras ser nada, ni menos saben quién es el héroe" (p. 50).

Si Don Quijote cumple en el ensayo de Unamuno la función que se acaba de exponer, la figura de Sancho adquiere también connotaciones precisas, no reflejadas hasta entonces por ningún exégeta de la obra original. Ni siquiera el propio Cervantes, a juicio del escritor bilbaíno, supo acertar a descubrir la esencia del personaje fruto de su creación. No debe extrañar este presupuesto, repetidamente manifestado por Unamuno en diversos lugares, pues, en su personal visión creadora, "los personajes de ficción tienen dentro de la mente del autor que los finge una vida propia, con cierta autonomía, y obedecen a una íntima lógica de que no es del todo consciente ni dicho autor mismo"14. Por ello, corrige a Cervantes cuando, en la misma presentación de Sancho, decía de él que tenía "muy poca sal en la mollera", indicando que esa afirmación es gratuita y que, no sólo la desmiente su actuación en la novela, sino que aporta, además, un argumento de tipo ético, pues "en rigor no cabe hombría de bien, verdadera hombría de bien, - dirá Unamuno - no habiendo sal en la mollera, visto que en realidad ningún majadero es bueno" (p. 51).

Sancho, conviene repetirlo, no es ningún tonto. Tiene, normalmente, buen juicio; a veces, y esto lo nota muy bien don Miguel, peca por exceso y, entonces, sí puede disentir de

\footnotetext{
${ }^{14}$ Del prólogo a la segunda edición en 1913 (VDQS, p. 20). También en las palabras preliminares a la tercera edición (1930), volverá a insistir de nuevo: “[...] Don Quijote y Sancho son — no es sólo que lo fueron- tan independientes de la ficción poética de Cervantes como lo es de la mía aquel Augusto Pérez de mi novelaNiebla" (p. 22).
} 
su amo o enfrentarse abiertamente a él. Pero, en cualquier caso, aquel calificativo debe ser reservado a otros: los duques, por ejemplo. Estos antipáticos personajes gastan tanto tiempo y esfuerzo en fabricar burlas a los protagonistas que el propio narrador cervantino afirma que "tiene para sí ser tan locos los burladores como los burlados, y que no estaban los Duques a dos dedos de parecer tontos, pues tanto ahínco ponían en burlarse de los tontos ${ }^{95}$, pero el rector salmantino, mucho menos condescendiente aún, no se para en barras y corrige de nuevo, con cierta brusquedad, al autor primigenio:

"Alto aquí, que ni a Don Quijote ni a Sancho puede llamárseles tontos y sí a los Duques, que lo eran, y de remate y capirote, y tontos, como todos los tontos suelen serlo, maliciosos y bellacos. No hay, en efecto, tonto bueno; el tonto, y más si es amigo de burlas, rumia el pasto amargo de la envidia" (p. 264)

Sancho es, para el ensayista comentador, el complemento necesario del caballero; pero no tanto con la intención de dar cabida en la obra a un elemento que se le oponga con sus actuaciones, sino para construir un sujeto con el que pueda dialogar en voz alta, ofreciéndonos, de primera mano, sus pensamientos más íntimos o la justificación de su modo de proceder, sin necesidad de que el lector los conozca ya digeridos previamente por la figura del narrador omnisciente. Don Quijote se explica a sí mismo a través de sus parlamentos con Sancho y en Sancho escucha, antes que en ningún otro la voz de toda la humanidad ${ }^{17}$.

El lector avisado tal vez quiera recordar aquí que fue el deseo de medrar el que arrastró al labriego a salir de su patria, pero, incluso admitiéndolo, habría ya que reconocer en Sancho un asomo de idealismo. De lo contrario, cómo aspirar al gobierno de una ínsula. Por ello, Unamuno señala este rasgo desde el principio de su comentario: "De la parte de Sancho empecemos a admirar su fe, la fe que por el camino de creer sin haber visto le lleva a la inmortalidad de la fama, antes ni aun soñada por él siquiera y al esplendor de su vida" (p. 52). De este modo, si en Sancho hay codicia y sed de oro, no hay menos ansia de fama y de gloria, - como se pondrá de manifiesto cada vez más acusadamente en la segunda parte de la obra-, y será, finalmente, este anhelo de inmortalidad el que acabará uniendo a ambos personajes.

Es fácil, pues, observar cómo Unamuno se centra por completo en lo que podríamos denominar el trasfondo vivencial de estas dos figuras. Así, si Cide Hamete Benengeli cuenta la historia de ellos, el rector salmantino la analiza desde el interior de los personajes. El primero refiere lo que hacen, el segundo sabe por qué lo hacen. El escritor arábigo se interesa por la verdad histórica, Unamuno por su intrahistoria.

Siguiendo este camino, se acaba por llegar a otra de las tesis más interesantes y provocadoras de don Miguel: su afirmación de que Don Quijote y Sancho han tenido una

\footnotetext{
${ }^{15}$ Cap. LXIX de la Segunda Parte.

${ }^{16}$ Unamuno se atreve a ir más allá y a ofrecernos una razón de la actitud aviesa de estos innobles personajes ducales: "En el fondo no perdonaban los Duques a Don Quijote el renombre por este adquirido y aspiraban a unir su nombre al nombre inmortal del Caballero. Pero bien los castigó el sabio historiador pasando en silencio sus nombres, con lo cual no lograron su propósito. En "los Duques" a secas se quedarán, y como cifra y compendio de Duques sandios y malintencionados" (p. 264).

17 “Ya está completado Don Quijote. Necesitaba a Sancho. Necesitábalo para hablar, esto es, para pensar en voz alta sin rebozo, para oírse a sí mismo y para oír el rechazo vivo de su voz en el mundo. Sancho fue su coro, la humanidad toda para él. Y en cabeza de Sancho ama a la humanidad toda” (pp. 51-52).
} 
existencia real e histórica. Escojamos un solo pasaje bien definitorio al respecto, el comentario que hace a las palabras del cura cuando, en la venta, opone las mentiras que en los libros de caballerías se atribuyen a sus protagonistas frente a la historia verdadera de algunos guerreros famosos:

"Vuestra merced debe saber por sus estudios lo de operari sequitur esse, el obrar se sigue al ser, y yo le añado que sólo existe lo que obra y existir es obrar, y si Don Quijote obra, en cuantos le conocen, obras de vida, es Don Quijote mucho más histórico y real que tantos hombres, puros nombres que andan por esas crónicas que vos, señor Licenciado, tenéis por verdaderas. Sólo existe lo que obra" (p. 118) ${ }^{18}$.

Unamuno, en un rasgo muy propio del ensayo, llega a prometer a sus lectores escribir un nuevo libro dedicado expresamente a probar la existencia real de ambos personajes, en el que sacará a la palestra razones y autoridades que lo abonen; pero, en cualquier caso, no aceptar su proposición supondría negar también - añade con un claro deje de ironía - otras muchas cosas generalmente aceptadas por la sociedad de su tiempo, con lo cual, concluye, "vendríamos a zapar y a socavar el orden en que se asienta hoy nuestra sociedad, orden que, como es sabido, es hoy el criterio supremo de la verdad de toda doctrina" (p. 119).

Ahora puede comprenderse mejor el significado que alcanza el título de la obra unamuniana, Vida de Don Quijote y Sancho. Un título, pues, que no es sólo un rótulo sino una auténtica declaración de intenciones. El sustantivo vida muestra aquí el significado de la primera de las acepciones que el diccionario de la Academia otorga al término, esto es, 'fuerza o actividad interna sustancial, mediante la que obra el ser que la posee'. Al aplicar esta significación básica, que recoge los conceptos ampliamente repetidos por don Miguel en su ensayo (ser, obrar, fuerza motora íntima), don Miguel muestra, una vez más, su capacidad como maestro del lenguaje en su prurito de exactitud. Ha desestimado otras posibilidades desde el título primigenio que aparece al frente del borrador manuscrito que se conserva en su Casa Museo de Salamanca: Las vidas de Don Quijote y Sancho según Miguel de Cervantes Saavedra, explicadas y comentadas por Miguel de Unamuno ${ }^{19}$. El rector salmantino, como puede observarse, ha procedido por decantación. De ahí que donde se hacía constar un largo encabezamiento, más propio de un libro erudito, se eliminen, de un lado, la segunda parte del mencionado título provisorio $\mathrm{y}$, de otro, se realce el valor generalizador en el sustantivo que sirve de eje a dicho título.

Con respecto a lo primero, Unamuno siempre desdeñó la erudición, y más aún el cervantismo al uso, que hacía, en su opinión, de la genial producción cervantina un mero monumento. "La letra mata" solía decir y escribir con frecuencia el rector de Salamanca, porque a él no le interesaba más la literatura que la propia existencia del ser humano con su componente esencial de eternidad. Razón también por la cual se ponía furioso cuando alguien lo calificaba de "hombre de letras", siguiendo el dictamen francés a la moda.

\footnotetext{
${ }^{18}$ Valiéndose de una de sus geniales paradojas, continuará este planteamiento del siguiente tenor: "Ese investigar si un sujeto existió o no existió proviene de que nos empeñamos en cerrar los ojos al misterio del tiempo. Lo que fue y ya no es, no es más que lo que no es, pero será algún día; el pasado no existe más que el porvenir ni obra más que él sobre el presente. ¿Qué diríamos de un caminante empeñado en negar el camino que le resta por recorrer, y no teniendo por verdadero y cierto sino el recorrido ya? Y ¿quién os dice que los sujetos cuya existencia real negáis no han de existir un día, y, por tanto, existen ya en la eternidad, y hasta que no hay nada concebido, lo cual en la eternidad no sea real y efectivo?" (p. 118).

${ }^{19}$ Véase la reproducción fotográfica que figura en la edición de Alberto Navarro, p. 132.
} 
Unamuno viene a subrayar con su atinada corrección que su interés se centra, frente a Cervantes, en la vida auténtica que desbordan aquellos personajes que, a su juicio, sobrepasaban ampliamente a su creador, quien nunca llegaría a conocerlos en su más íntima esencia, reduciendo el papel del alcalaíno al de mero historiador que deja noticia de unos hechos que ha conocido. Tampoco quiere que el término explicadas que aparece en el mencionado borrador se malinterprete por parte del lector y le atribuya a su creación personal un sentido académico próximo a su quehacer docente universitario, de manera que se confundiera su ensayo con un tratado al uso.

Respecto de la segunda modificación sufrida hasta llegar al marbete definitivo del libro, la supresión del artículo y el paso del sustantivo a su forma definitiva en singular, obedece también a ese amor radical por los protagonistas de la obra cervantina y al carácter de existencia real que les atribuye. El sustantivo obtiene así su mayor grado de potencialidad, evitando cualquier delimitación del nombre, todo valor deíctico. El término vida marca la progresiva separación entre los acontecimientos que se narran en el original cervantino y el valor espiritual que dicho término alcanza en la producción unamuniana. Por otra parte, la misma singularización del vocablo parece unir más aún a Don Quijote y a Sancho en su discurrir existencial, no ya como si ambos fueran las dos caras de una misma moneda, sino, mejor incluso, como un auténtico tejido cuya trama y urdimbre son difíciles de distinguir a simple vista en el paño que sale del telar. Don Quijote y Sancho son, nadie lo duda, personajes distintos; no se trata de esos personajes geminados y planos de otro tipo de relatos que siempre van juntos, de manera que lo que uno dice o hace resulta fácilmente intercambiable con lo de su pareja. Cada uno mantiene su propia identidad, pero, y aquí radica la fuerza medular que los desarrolla, cada uno se nutre de la palabra y de las acciones del otro $^{20}$. Sancho está tentado en ocasiones a abandonar a su amo y Don Quijote, por su parte, desea verse libre de su locuaz escudero; pero, cuando el primero se ve rechazado por el caballero, no puede sino llorar amargamente y pide ser perdonado y readmitido, y, cuando el segundo no tiene a mano a su escudero, lo lamenta profundamente hasta sentirse perdido. La fe de ambos se sostiene recíprocamente, porque Sancho es también representante de la fe, de la fe en su señor y de la fe que duda —única fe posible para Unamuno-

También en este aspecto cabe plantear una importante diferencia entre Cervantes y Unamuno. Don Quijote, al inicio de la novela original, es un personaje caracterizado por una fe diamantina que, sin embargo, conforme avanza la segunda parte, se irá debilitando y el protagonista estará obligado a hacer concesiones cada vez mayores al poder de los encantadores o al propio Sancho. Por el contrario, en la obra unamuniana, el hidalgo manchego se muestra cada vez más enfebrecido por su inmarcesible ideal. Incluso en su derrota caballeresca, le hará idear ese futuro Quijotiz con una proyección que está ausente en el texto cervantino y de la que participará, finalmente, el mismo Sancho, cuando estando aquél en su lecho de muerte ya no vea sino por los ojos de su señor. Por ello, el rector de Salamanca, más exaltado conforme se acerca el final de su ensayo, comentará acerca de esta proposición última:

${ }^{20}$ Para Ricardo Gullón: "Situar a Sancho en el título de la novela (sic) implicaba ya una toma de posición autorial beneficiosa para el escudero y en nada reductora para el caballero. Según progresa el texto irá declarándose la correlación de los actantes, su complementariedad y el movimiento que siendo inverso, les acercará tan visiblemente a lo llamado por Unamuno quijotización se Sancho y sanchificación de Don Quijote" (“Introducción”, $V D Q S$, p. VIII-IX). 


\begin{abstract}
"El ansia de gloria y de renombre es el espíritu íntimo del quijotismo, su esencia y su razón de ser, y si no se puede cobrarlos venciendo gigantes y vestiglos y enderezando entuertos, cobrárselos endechando a la luna y haciendo de pastor. El toque está en dejar nombre por los siglos, en vivir en la memoria de las gentes. ¡El toque está en no morir! ¡En no morir! ¡En no morir! Esta es la raíz última, la raíz de las raíces de la locura quijotesca. ¡No morir! ¡No morir! Ansia de vida; ansia de vida eterna es la que te dio vida inmortal, mi señor don Quijote; el sueño de tu vida fue y es sueño de no morir" (p. 250).
\end{abstract}

Esto es, mientras el Don Quijote de Cervantes se va empequeñeciendo y apocando conforme se acerca el final de la novela, el hidalgo unamuniano se va creciendo en la adversidad que, aunque cierta, no le impide una trascendencia muy cercana a la de la actividad profética, una actuación que conlleva tanto la predicación de un modelo de vida como la incomprensión que recibe de aquellos a los que entrega sus palabras y sus hechos. Es más, para don Miguel, incluso el momento final del hidalgo en el que manifiesta haber recuperado la cordura no es una prueba del error en que se mantuvo en vida, sino una prueba más de heroísmo:

"Tu muerte fue más heroica que tu vida, porque al llegar a ella cumpliste la más grande renuncia, la renuncia de tu gloria, la renuncia de tu obra. Fue tu muerte encumbrado sacrificio. En la cumbre de tu pasión, cargado de burlas, renuncias, no a ti mismo, sino algo más grande que tú: a tu obra. Y la gloria te acoge para siempre” (p. 273).

Y Unamuno, una vez más, enmienda la plana a Cervantes, pues con la muerte de Don Quijote no se pone fin a esa manera de proceder por la que se condujo durante toda su vida. Sin esperarlo, tal vez, ha pasado el testigo a su heredero. Sancho se ha inoculado de la locura vivificante del idealismo quijotesco y será su continuador.

“ $¡$ Oh heroico Sancho y cuán pocos advierten que ganaste la cumbre de tu locura cuando tu amo se despeñaba por el abismo de la sensatez y que sobre su lecho de muerte irradiaba tu fe, tu fe, Sancho, la fe en ti, que ni has muerto, ni morirás! Don Quijote perdió su fe y muriose; tú la cobraste y vives; era preciso que él muriera en desengaño para que en engaño vivificante vivas tú" (pp. 274-275).

Por Sancho, que queda vivo y llorando a su amo en la novela, se cumplirán, definitivamente, las promesas del hidalgo y será, asimismo, el artífice de la resurrección del caballero. A éste último invocará don Miguel en un largo parlamento con palabras de consuelo, aunque no sepamos bien si ese consuelo pretende aliviarle al hidalgo el dolor de su renuncia o confortar al propio Unamuno que quiere hacerse fuerte en la esperanza:

"Sancho, que no ha muerto, es el heredero de tu espíritu, buen hidalgo, y esperamos tus fieles en que Sancho sienta un día que se le hincha de quijotismo el alma [...]. Y entonces, Don Quijote mío, entonces es cuando tu espíritu se asentará en la tierra. Es Sancho, es tu fiel Sancho, es Sancho el bueno, el que enloqueció cuando tú curabas de tu locura en tu lecho de muerte, es Sancho el que ha de asentar para siempre el quijotismo sobre la tierra de los hombres. Cuando tu fiel, Sancho, noble caballero, monte en tu Rocinante, revestido de tus armas y embrazando tu lanza, entonces resucitarás en él, y entonces se realizará tu ensueño" (p. 276).

Esta esperanza final en Sancho justifica, de manera clara, por qué Unamuno se centra sólo en estos dos personajes y los iguala en su consideración hasta el punto de hacer mención del escudero en el propio título de su ensayo. Si Don Quijote es el iniciador de la empresa, el profeta de la regeneración que España necesita, Sancho es su heredero y el 
mesías en el que se cumplirá la promesa. Frente a ellos dos, que representan la vida, la vida auténtica - a la que se hace referencia, conviene recordarlo una vez más, desde el mismo título: Vida de Don Quijote y Sancho-, el resto de personajes de la obra cervantina queda sumergido en esa niebla que invade también los discursos tan celebrados por los eruditos, los hechos que nada aportan al trasfondo vivencial del héroe y su acompañante o los relatos ajenos al personaje central. Pero, si alguno de aquéllos personajes sale a relucir, no saldrá bien parado, como le ocurrirá a Antonia Quijana, la sobrina, en las páginas finale ${ }^{21}$.

Y es que los antagonistas del héroe lo son también de la propia España. Si Don Quijote y su escudero encierran, para Unamuno, la fuerza del ideal, la voluntad como estandarte, el deseo de hacerse a sí mismos; ellos serán también el modelo en que debe mirarse la patria en ese estado de postración en que está sumida. Don Miguel, al que tampoco le era ajeno nada de lo humano, $\mathrm{y}$ al que preocupa lo trascendente sin olvidar lo inmediato del acontecer diario, salpica su ensayo de constantes proposiciones referidas a la situación española contemporánea; pero que, como siempre ocurre con las obras cimeras, son de una inmediatez conmovedora para el hombre de hoy. No debe olvidarse que Unamuno se sabía herido por un mal tremendo que acabaría siendo la causa desencadenante de su muerte en el fatídico 1936, un mal que él había sintetizado con la desesperación de un grito formidable: “¡Me duele España!”. Y así, dirá de Don Quijote, cuyo ánimo inconcuso le lleva a las más desaforadas aventuras, que:

"Ese es el valor que necesitamos en España, y cuya falta nos tiene perlesiada el alma. Por falta de él no somos fuertes, ni ricos, ni cultos; por falta de él no hay canales de riego, ni pantanos, ni buenas cosechas [...] ¿Qué también os parece paradoja? Id por esos campos y proponed a un labrador una mejora de cultivo o la introducción de una nueva planta o una novedad agrícola y os dirá: "Eso no pinta nada aquí." "LLo habéis probado?", preguntaréis, y se limitará a repetir: "Eso no pinta nada aquí." Y no sabe si pinta o no pinta, porque no lo ha probado, ni lo ensayará nunca” (p. 129).

Pero la razón de esto él mismo la declara: no es el mero inmovilismo lo que la motiva o la falta de interés en posibles mejoras, de cuyo resultado el emprendedor sería el primer beneficiado; sino el terror que siente el español a que se burlen de él, el miedo al ridículo que acaba por atenazarlo. De manera que la única solución es perder la vergüenza a equivocarse poniendo los ojos en el resultado y, aunque éste fuera desfavorable, el consuelo unamuniano ya es alentador: "Sólo el que ensaya lo absurdo es capaz de conseguir lo imposible" (p. 130).

Lo que sobra a Don Quijote falta a nuestro pueblo: la valentía, el arrojo, la fe en sí mismo por encima del qué dirán. De ahí que Unamuno lance un improperio general a la España de su tiempo: "Sí, todo nuestro mal es la cobardía moral, la falta de arranque para afirmar cada uno su verdad, su fe, y defenderla. La mentira envuelve y agarrota las almas de esta casta de borregos, estúpidos por opilación de sensatez" (p. 130).

Ante estas afirmaciones, ciertamente revolucionarias —entonces y ahora-, los lectores no pueden sentirse indiferentes. Cada uno de éstos, con la misma inmediatez que él los trata de tú y con esa reminiscencia evangélica que siempre imprime a sus palabras, podría preguntarle también a él directamente: “¿soy yo, acaso, uno de éstos, don Miguel?”. Y es que ese receptor, al que Unamuno apela con un cordial "lector mío" - en singular y con posesivo - es siempre una persona, un individuo concreto que sigue sus palabras como en

${ }^{21} V D Q S$, pp. 279 y ss. 
un itinerario íntimo y al que hace partícipe de sus confidencias. No se dirige nunca don Miguel a un conjunto más o menos uniforme, ni mucho menos a un determinado público. Si él pudiera, imprimiría especialmente el nombre en cada lector en el ejemplar que éste tiene entre sus manos y, como esto es imposible, agrega al sustantivo el posesivo mío. Ignora, pues, nuestro nombre de pila, pero el uso de este adjetivo efectúa una labor especificativa y claramente diferenciadora; los que se acercan a sus libros no son simplemente lectores, masa de un colectivo inconexo, tampoco son receptores ocasionales que, como por sorpresa, se enfrentan a su trabajo, ni responderían al apelativo mostrenco de "curioso lector". Menos aún, admitiría el rector salmantino la fórmula cervantina con la que se inicia El Quijote, donde se solicita al "desocupado lector" que preste atención a la historia que se sigue, pues Unamuno necesita destinatarios ocupados, y preocupados, para que sus recurrentes ideas caigan como semillas en tierra capaz de dar fruto.

El autor de la Vida de Don Quijote y Sancho, como Sísifo, emprende una labor sobrehumana, la de acompañar a cada lector por las páginas de su libro desde el inicio hasta el final, y, como aquel rey mitológico, sabe que deberá comenzar de nuevo, interminablemente, pues el lector sólo se sentirá conmovido, y confortado, al notar la mano vigorosa de don Miguel que aprieta la suya a la vez que pronuncia sus terribles palabras, del mismo modo que Dante se aventura a recorrer los nueve círculos infernales de la mano de Virgilio.

Cómo, si no, se atrevería él a decir, y nosotros a escuchar, palabras tan duras como éstas aplicadas a la situación de España:

"Se proclama que hay principios indiscutibles, y cuado se trata de ponerlos en tela de juicio no falta quien ponga el grito en el cielo. [...] Estoy harto de oír llamar inoportunas a las cosas más oportunas, a todo lo que corta la digestión de los hartos y enfurece a los tontos. ¿Qué se teme? ¿Qué se trabe y se encienda la guerra civil de nuevo? ¡Mejor que mejor! Es lo que necesitamos.

Sí, es lo que necesitamos: una guerra civil. Es menester afirmar que deben ser y son yelmos las bacías y que se arme sobre ello pendencia como la que se armó en la venta. Una nueva guerra civil, con unas o con otras armas" (pp. 130-131).

Pero no es Unamuno ningún nihilista al uso que, por no creer en nada, se complace en la destrucción. Al contrario, porque cree, y cree firmemente como Don Quijote, se atreve a levantar pendencia. Es, eso sí, un provocador, un agitador de conciencias. Tomando por modelo la figura del hidalgo, pone, y pide también que se pongan, las cartas boca arriba. Sabe que, en cuanto alguien escuche las palabras más arriba citadas, saldrán a su encuentro para oponer a sus argumentos las ventajas de la paz. Pero él aclarará enseguida que el problema no es de términos, sino de conceptos. Cuál es su guerra y cuál es la paz que se le ofrece. Su guerra es la del sentimiento trágico de la vida, la del cristianismo quijotesco, la que, en definitiva, pretende desterrar la mentira. La paz que le ofrecen es un falso lenitivo de conformidad en la derrota, una atonía envilecedora de la vida, una ataraxia paralizante del individuo y de la sociedad española o, en sus propias palabras, "una paz más mortal que la muerte misma" (p. 130). Los que proponen esta paz son los nuevos bachilleres, licenciados, sobrinas y cuadrilleros de la Santa Hermandad ${ }^{22}$ contra los que este nuevo

22 “¡Paz!, ¡paz!, ¡paz! Croan a coro todas las ranas y los renacuajos todos de nuestro charco. ¡Paz!, ¡paz!, ¡paz! Sí, sea, paz, pero sobre el triunfo de la sinceridad, sobre la derrota de la mentira. Paz, pero no una paz de 
apóstol del quijotismo levanta la voz de una manera radical e intransigente. Frente a ellos, y en abono de su teoría, Unamuno acude nada menos que a las palabras del mismo Cristo, en nombre del cual muchos solicitan resignación y encogimiento:

"Y esos desdichados que gritan "ipaz!, ipaz!” se atreven a tomar en labios el nombre de Cristo. Y olvidan que el Cristo dijo que Él no venía a traer paz sino guerra, y que por Él estarían divididos los de cada casa, los padres contra los hijos, los hermanos contra los hermanos. Y por Él, por el Cristo, para establecer su reinado, el reinado social de Jesús [...], el reinado de la sinceridad y de la verdad y del amor y de la paz verdaderos; para establecer el reinado de Jesús tiene que haber guerra.

¡Razas de víboras la de esos que piden la paz! Piden paz para poder morder y roer y emponzoñar más a sus anchas" (p. 132).

Palabras de esta contundencia no debían agradar, sin duda, a aquéllos que él consideraba como una especie de nuevos mercaderes del templo, máxime cuando el argumento de autoridad que sirve de apoyo a don Miguel les resultaba irrevocable, ¿podrían contradecir también al mismo Dios al que afirmaban seguir? ${ }^{23}$ Tenían que conformarse tan sólo con aplicarle al rector salmantino el calificativo de heterodoxo, lo cual tampoco debía hacer mucha mella en él, porque, más que enfrentarse a la ortodoxia, a Unamuno le importaba proclamar su propia verdad. Sería, en todo caso, un "autodoxo", esto es, alguien que se preocupa en fijar y proclamar "su" verdad, independientemente del rechazo o la adhesión que su doctrina consiga entre sus receptores. Esta fe en una verdad, creada por él y sostenida con la fuerza de su brazo, será, como la de don Quijote, la única que puede salvarlo ${ }^{24}$. También en esto don Miguel se nos muestra paradójico — calificación con la que zaherían a menudo sus escritos-, pero en el mejor de los sentidos, es decir, en el de quien manifiesta opiniones distintas al sentir general y que, aunque aparentemente puedan envolver una contradicción, sin embargo de ellas se desprende un pensamiento nuevo y fecundo.

No dejará Unamuno tranquila la conciencia de los hombres y su labor de agitador espiritual de los españoles no conocerá la tregua ${ }^{25}$. La paz es radicalmente distinta de esa especie de atonía mental que los envuelve y la vida verdadera no puede abordarse con la táctica del avestruz. Al igual que don Quijote agitó la conciencia de Sancho Panza y le impulsó a seguirlo entre sus dudas, él pretende con su ensayo despertar el adormecido

compromiso, no un miserable convenio como el que negocian los políticos, sino paz de comprensión. Paz, sí, pero después que los cuadrilleros reconozcan a Don Quijote su derecho a afirmar que la bacía es yelmo; más aún: después que los cuadrilleros confiesen y afirmen que en manos de Don Quijote el yelmo es bacía” (pp. 130-131).

23 "No penséis que he venido a traer paz a la tierra. No he venido a traer paz, sino espada. Sí, he venido a enfrentar al hombre con su padre, a la hija con su madre, a la nuera con su suegra; y sus propios familiares serán los enemigos de cada cual" (Mt 10, 34-37). Unamuno, tan buen conocedor de los textos bíblicos, se presenta aquí ante sus contemporáneos como el propio Jesús ante los hombres de su época, esto es, como señal de contradicción. El texto evangélico que inspira sus palabras no ha podido estar mejor escogido. Unamuno, como el Maestro, sabe que la radicalidad de su mensaje no admite componendas y ello provocará discordias y, en todo caso, depende de la libre elección del individuo.

24 "Yo forjo con mi fe, y contra todos, mi verdad, pero luego de así forjada ella, mi verdad se valdrá y se sostendrá sola y me sobrevivirá y viviré yo de ella" (p. 244).

${ }^{25}$ La despedida que ofrece Del sentimiento trágico de la vida no puede ser más reveladora de esta inquietud provocadora: "Espero, lector, que mientras dure nuestra tragedia, en algún entreacto, volvamos a encontrarnos. Y nos reconoceremos. Y perdón si te he molestado más de lo debido e inevitable, más de lo que al tomar la pluma para distraerte un poco de tus ilusiones me propuse. ¡Y Dios no te dé paz y sí gloria!” (ob. cit., p. 321). 
ánimo de sus conciudadanos, pues no es verdadero hombre sino quien se sabe tal y ahí radica la condición de su gloria ${ }^{26}$. Por ello, el vítor de Unamuno en su Casa Museo de Salamanca lleva una divisa tan escueta como esclarecedora de su personalidad: "Primero la verdad que la paz"27.

En la Vida de Don Quijote y Sancho se ponen de manifiesto, en definitiva, aspectos fundamentales del existencialismo filosófico como son la libertad del ser humano y su capacidad de elección atendiendo a la realidad concreta en la que se desarrolla cada individuo. Esto implica, de un lado, el rechazo de modelos universales y objetivos; de otro, la aceptación del subjetivismo plantea, dentro de esa libertad del individuo para construir su existencia, continuos conflictos de elección, ya que aquél no puede escudarse en ninguna doctrina prefijada. Unamuno, de la mano de Kierkegaard, admite que el bien más elevado para el individuo es encontrar su propia y única vocación. Por eso, el hidalgo manchego encarna sobremanera este ideal existencialista y le interesa tanto su glosa al rector de Salamanca.

Este sentido de la libertad es el que le hará decir de Don Quijote enjaulado, al final de la Primera Parte, que "será siempre libre el libre" (p. 136) y que "no hay hombre capaz de enjaular a otro hombre" (p. 136), porque el secreto, nos avisa, reside en que todo individuo sepa ejercitarse en esa capacidad de pensar que por naturaleza posee, como hace siempre el caballero cervantino, y no se conforme con una mera petición de libertad lanzada al vacío. Don Quijote es, pues, libre porque ha escogido serlo y, a partir de ahí, sus actos son fruto de su responsabilidad, de su compromiso con el mundo que le rodea. Acepta sus riesgos y sabe que sus acciones pueden volvérsele en contra, como cuando liberó a los galeotes; pero Unamuno advierte que no se debe esperar gratitudes en la tierra ${ }^{28} \mathrm{y}$, menos aún, de quienes no conocen el verdadero sentido de la libertad. A pesar de todo, el héroe cervantino, como el hombre auténtico, no puede actuar sino ejerciendo su libertad y ofreciendo a los demás esa misma posibilidad de obrar, aunque éstos la rechacen con violencia, porque el ejercicio de la libertad genera angustia y algunos prefieren ignorarla, amparándose en la comodidad; de manera que sugerir esta posibilidad es desasosegar sus acomodaticios espíritus ${ }^{29}$.

\footnotetext{
26 "Hay espíritus menguados — afirma Unamuno- que sostienen que es mejor ser cerdo satisfecho que no hombre desgraciado, y los hay también para endechar a la que llaman santa ignorancia. Pero quien haya gustado la humanidad, la prefiere, aun en lo hondo de la desgracia, a la hartura del cerdo. Hay pues, que desasosegar a los prójimos los espíritus, hurgándoselos en el meollo, y cumplir la obra de misericordia de despertar al dormido cuando se acerca un peligro o cuando se presenta a la contemplación alguna hermosura. Hay que inquietar lo espíritus y enfusar en ellos fuertes anhelos, aun a sabiendas de que no han de alcanzar nunca lo anhelado" (p. 149150).

${ }^{27}$ Cfr. Alberto Navarro, "Introducción”, cit., p. 53.

28 "Lo cual debe enseñarnos a libertar galeotes precisamente porque no nos lo han de agradecer, que de contar de antemano con su agradecimiento, nuestra hazaña carecería de valor. Si no hiciéramos beneficios sino por las gratitudes que de ellos habríamos de recoger, ¿para qué nos servirán en la eternidad? Debe hacerse el bien no sólo a pesar de que no nos han de corresponder en el mundo, sino precisamente porque no han de correspondérnoslo. El valor infinito de las buenas obras estriba en que no tienen pago adecuado en la vida, y así rebosan de ella. La vida es un bien muy pobre para los bienes que en ella cabe ejercer." (p. 97).

29 "Si les rompes las cadenas de la cobardía que les tienen presos; te apedrearán. Te apedrearán. Los galeotes espirituales apedrean al que rompe las cadenas que les agarrotan. Y precisamente por esto, porque ha de ser uno apedreado por ellos, es por lo que hay que libertarlos. El primer uso que de su libertad hacen es apedrear al libertador. El más acendrado beneficio es el que se hace al que no nos lo reconoce por tal: la mayor caridad que puedes rendir a tu prójimo no es aplacarle deseos ni remediarle necesidades, sino encenderle aquellos y crearle éstas. Libértale, y luego que te apedree por haberle libertado y ejercite así sus brazos libres, empezará a desear la
} 
Por ello, una de las obsesiones más recurrentes en el conjunto de la producción unamuniana será la de hacerse a sí mismo mediante el establecimiento de su propia verdad y, de este modo, alcanzar la inmortalidad a la que aspira. Una inmortalidad que se gana por la vía de la insistencia, de hacerse presente ante Dios y de reclamar ante él nuestro derecho a la eternidad como criaturas suyas. La obligación de cada individuo es hacer que Dios no se olvide de él y sólo en esto debe consistir su vida:

"Si por guardar tu mecha apagas la luz: si por ahorrar tu vida malgastas tu idea, Dios no se acodará de ti anegándote en su olvido como en perdón supremo. Y no hay otro infierno que éste: el que Dios nos olvide y volvamos a la inconsciencia de que surgimos [...]. Si aspiro a $\mathrm{Ti}$, viviré en Ti; si de Ti me aparto, iré a dar en lo que no es tuyo, en lo único que fuera de Ti cabe, en la nada" (pp. 245-246).

En conclusión, la Vida de Don Quijote y Sancho trasciende, pues, cualquier tipo de comentario erudito o filológico del original cervantino. Se trata, por encima de todo, de una genial obra literaria; de un ensayo que aúna cualidades estéticas de primer orden y profundas reflexiones sobre el valor intemporal del ser humano, el contexto histórico de la España que inicia el siglo XX y el propio autor, que desnuda su alma con una carga lírica incontestable, con esa genial amalgama de la que el escritor bilbaíno supo servirse para construir su obra, en prosa y verso. Lo colectivo y lo individual, en sus más diversas vertientes, encuentran eco siempre en Unamuno. Los que lo acusan despectivamente de ególatra desconocen que quien ha seguido el imperativo clásico del "conócete a ti mismo" sólo de esas íntimas aproximaciones puede hablarnos con un cierto fundamento y, esto, para ofrecerse desnudo, a la manera de una confesión general de la que nos hace partícipes a todos sus lectores. Sus miedos, sus angustias, sus deseos proceden de esa confrontación entre sus íntimos y maduros hallazgos y el deseo de que sus lectores sean también prosélitos. Como Don Quijote hablaba a todos de una caballería andante que sólo existía en su corazón, pero que para él era tan viva, tan real, tan verdadera, que aun le hacía ver una realidad trastocada y cambiante por encantamiento; Don Miguel habla a todos con la voz adusta del profeta que conocedor de la verdad revelada está pendiente siempre de su salvación y de la de los otros. El que sabe la buena noticia no puede ocultarla a sus semejantes. Distinto será que éstos quieran escucharla, y, sobre todo, seguirla. 